\title{
O087: An acinetobacter spp. (GIM-1) pseudo- outbreak due to contamination of a pneumatic transport system (PTS) in a large university hospital
}

\author{
BC Gärtner ${ }^{\text {* }}$, S Jungmann ${ }^{1}$, A Dawson ${ }^{1}$, A Halfmann ${ }^{1}$, C Petit ${ }^{1}$, M Kaase², SG Gatermann², M Klotz ${ }^{1}$, L von Müller ${ }^{1}$,

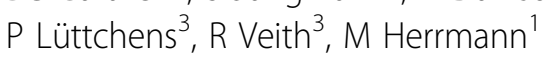

From 2nd International Conference on Prevention and Infection Control (ICPIC 2013)

Geneva, Switzerland. 25-28 June 2013

\section{Introduction}

In clinical specimen from 21 patients, two species of Acinetobacter baumannii complex were isolated with resistance to betalactams including carbapenems. None of the patients had symptoms indicative for infection. Patients were treated in various departments and a large spectrum of age, clinical specimen, and underlying disease was observed.

\section{Objectives}

To identify the source of transmission.

\section{Methods}

Molecular analysis of the isolated strains and extensive epidemiologic workup.

\section{Results}

Molecular analysis confirmed presence of a metallobetalactamase of GIM-1 genotype. Extended epidemiologic workup, however, did not reveal any factors for transmission, previous hospitalizations, common places of residence moreover Extensive analysis of specimen workup in the laboratory rendered a laboratory associated pseudo-outbreak highly unlikely.

Identical Acinetobacter spp (GIM-1) was found on 8/13 patient data sheets accompanying the positive specimen, as well as PTS cartridges prospectively analyzed. Positive microbiological results were associated with humidity in the cartridges. Moreover the outbreak strain was detected in air samples close to the PTS.

${ }^{1}$ Institute of Medical Microbiology and Hygiene, University of the Saarland, Homburg/Saar, Germany

Full list of author information is available at the end of the article
Upon identification of the PTS as cause of the pseudooutbreak, all clinical infection control measures were lifted, yet, rigorous measures for hygienic handling of PTS stations, cartridges, and transported specimens were introduced. Moreover, the PTS was decontaminated with disinfectants.

\section{Conclusion}

To our knowledge, this is the worldwide first description of a large-scale contamination of a hospital PTS. In absence of established environmental hygiene standards, bacterial contamination of PTS may occur for extended time periods prior to recognition, and may be the cause not only for pseudo-outbreaks but also for transmission of nosocomial pathogens with yet unknown consequences. This experience suggests that establishment of standards is necessary for the particular challenge which PTS may represent for hospital hygiene.

\section{Disclosure of interest}

None declared.

\section{Author details}

'Institute of Medical Microbiology and Hygiene, University of the Saarland, Homburg/Saar, Germany. ${ }^{2}$ National Reference Laboratory for Gram-negative Bacilli, University of Bochum, Bochum, Germany. ${ }^{3}$ Technical Department, University of the Saarland, Homburg/Saar, Germany.

Published: 20 June 2013

doi:10.1186/2047-2994-2-S1-087

Cite this article as: Gärtner et al:: 0087: An acinetobacter spp. (GIM-1) pseudo-outbreak due to contamination of a pneumatic transport system (PTS) in a large university hospital. Antimicrobial Resistance and Infection Control 2013 2(Suppl 1):O87.

\section{C)

(C) 2013 Gärtner et al; licensee BioMed Central Ltd. This is an Open Access article distributed under the terms of the Creative Commons Attribution License (http://creativecommons.org/licenses/by/2.0), which permits unrestricted use, distribution, and reproduction in any medium, provided the original work is properly cited. 